\title{
EFEKTIVITAS PENGGUNAAN MODUL FISIKA TERINTEGRASI STEM (SCIENCE, TECHNOLOGY, ENGINEERING, AND MATHEMATICS) MATERI USAHA DAN ENERGI DI SMA
}

\author{
${ }^{1)}$ Ella Maria Ulfa, ${ }^{1)}$ Subiki, ${ }^{1)}$ Lailatul Nuraini \\ ${ }^{1)}$ Program Studi Pendidikan Fisika FKIP Universitas Jember \\ Email: ellamariaulfa@gmail.com
}

\begin{abstract}
Learning carried out during the pandemic is required to develop technology to support student learning effectively. Solutions for students and teachers to carry out learning effectively by using learning media that students can understand independently at home. Learning media that can support students in independent learning are modules. The module usage by educators related to 21st-century skills to balance the world of education in the modern era can collaborate with models, methods, and approaches in learning, one of which is the STEM (Science, Technology, Engineering, and Mathematics) approach. The purpose of this research was to describe the effectiveness of the STEM integrated physics module. The research method is by giving tests to students in the form of pretest and posttest. The subjects of this study were students of MAN 1 Jember class X MIPA 2 as a limited test and X MIPA 3 broad test. Product testing was conducted by researchers using the One Group PretestPosttest design. Then analyzed normalized Gain (N-gain) to determine the effectiveness of the module. The results of the analysis of the effectiveness of the module in the limited test obtained an average $N$-gain of 0.55 in the medium category, while in the broad test it was 0.71 in the high category. Based on the results of the effectiveness analysis that the STEM integrated physics module is in the effective category.
\end{abstract}

Key word: Module, STEM, work and energy

\section{PENDAHULUAN}

Belajar merupakan kegiatan atau aktivitas mental (psikis) yang menghasilkan sebuah perubahan dan bersifat relatif konstan (Istiadah, 2020). Interaksi suatu pembelajaran dibangun dengan adanya kontrak dan komunikasi antara pelaksana pembelajaran (Nofrion, 2016). Proses pembelajaran memiliki prinsip dasar meningkatkan kemampuan yang dimiliki siswa dan membantu siswa mengetahui potensi apa saja yang mereka miliki (Simarmata et al., 2019:1-2). Pembelajaran fisika berperan dalam melatih peserta didik agar mampu menguasai ilmu pengetahuan, konsep serta prinsip fisika, mempunyai kecakapan ilmiah dan mempunyai keterampilan proses sains (Sukiminiandari et al., 2015: 162). Pada pembelajaran fisika perlu ditanamkan betul konsep dasar fisika hingga pengembangan keterampilan sains serta kemampuan berpikir siswa (Utami, et al., 2017: 68).

Munculnya pandemi covid 19 membuat kegiatan belajar mengajar terganggu. Selain itu, guru juga dituntut memanfaatkan teknologi dalam proses 
belajar mengajar (Efendi et al., 2021). Pelaksaanaan pembelajaran yang semula dilaksanakan disekolah sekarang menjadi belajar dirumah secara daring (Dewi, 2020: 59). Tantangan dalam belajar daring bukan hanya pada siswa melainkan pendidik juga diharuskan untuk menguasai penggunaan teknologi digital. Beberapa platform untuk menunjang kegiatan belajar mengajar secara dari mulai dari Whatsapp, Google Classroom, dan Zoom Meeting (Rahmadi, 2021:99). Meskipun kegiatan belajar secara daring, tujuan pembelajaran secara efektif akan tercapai jika guru mengemas pembelajaran secara menarik sesuai dengan karakteristik siswa (Rigianti, 2020: 298). Untuk menunjang pembelajaran yang efektif perlu adanya media pembelajaran.

Media pembelajaran dapat membantu peserta didik dalam menyampaikan materi saat proses pembelajaran berlangsung (Bekti et al., 2021) Media yang digunakan dalam proses pembelajaran disesuaikan dengan kondisi dan strategi yang digunakan oleh pendidik. Media pembelajaran yang dapat menunjang peserta didik dalam belajar mandiri yaitu modul (Puspitasari, 2019: 1718). Modul merupakan bentuk dari bahan ajar cetak yang digunakan pendidik dan peserta didik dalam suatu proses pembelajaran (Fatikhah \& Izzati, 2015: 49). Penggunaan/penyusunan modul oleh pendidik terkait keterampilan abad 21 untuk mengimbangi dunia pendidikan di era modern dapat dikolaborasikan dengan model, metode dan pendekatan dalam pembelajaran, salah satunya pendekatan STEM (Science, Technology, Engineering, And Mathematics) (Akaygun et al., 2016).

Krajcik \& Delen (2017: 37$)$
mendefinisikan STEM merupakan
akumulasi pengetahuan dari bebagai ilmu,
teknologi, teknik dan matematika sebagai
bidang yang terpisah tetapi saling terkait
satu sama lain. Pembelajaran terintegrasi
STEM mampu membimbing siswa dalam

mengaplikasikan ilmu pengetahuannya agar dapat menciptakan sebuah desain sebagai bentuk penyelesaian suatu masalah (Permanasari, 2016: 29-30). STEM mempunyai keunggulan jika dibandingkan dengan pendekatan yang mengintegrasikan lingkungan, teknologi dan masyarakat sebab pengajaran STEM mengintegrasikan konten dan keterampilan dalam pembelajaran (Fikri et al., 2019: 74). Melibatkan siswa dalam kegiatan STEM memungkinkan mereka untuk mengembangkan keterampilan berpikir tingkat tinggi (Pawilen \& Yuzon, 2019: 138).

Berdasarkan pemaparan latar belakang, peneliti melakukan penelitian tentang efektifitas modul fisika terintegrasi STEM (Science, Technology, Engineering, and Mathematics) pada pokok bahasan usaha dan energi dalam pembelajaran fisika. Beberapa penelitian yang dilakukan, pada tingkat menengah, siswa merasa kesulitan dalam pemahaman konsep usaha dan energi, terdapat beberapa siswa yang cenderung kesusahan dalam memahami konsep fisika (Darmawan, et al., 2019:42).

Hal ini dikarenakan salah satu permasalahan yang cukup kompleks yang terdapat dalam bidang mekanika yaitu materi usaha dan energi. Sehingga adanya permasalahan-permasalahan mengenai materi usaha dan energi, diperlukan sebuah modul pembelajaran untuk mempermudah siswa dalam memahami konsep-konsep terkait fisika (Hidayati dalam Maison, et al., 2020: 33). Tujuan dari penelitian ini untuk menganalisis efektifitas modul fisika terintegrasi STEM.

\section{METODE}

Jenis penelitian yang dilakukan termasuk dalam penelitian experiment. Tempat penelitian yang digunakan dalam penelitian ini adalah MAN 1 Jember. Subyek dalam penelitian ini adalah siswa kelas X MIPA 2 dan X MIPA 3 sebagai uji 
coba produk di MAN 1 Jember tahun ajaran 2020/2021. Pengujian produk yang dilakukan oleh peneliti menggunakan desain One Group Pretest-Posttest.

Metode yang digunakan untuk mengukur efektifitas modul fisika terintegrasi STEM dengan pemberian tes kepada siswa yaitu pretest dan posttest. Ujian awal atau pretest dilakukan di awal sebelum diberi perlakuan. Sehingga hasil perlakuan dapat diketahui lebih akurat dan dibandingkan dengan keadaan setelah diberi perlakuan. Gambaran desain untuk penelitian One Group PretestPosttest pada Gambar 1.

\begin{tabular}{|lll|}
\hline $\mathrm{O}_{1}$ & $\mathrm{X}$ & $\mathrm{O}_{2}$ \\
\hline
\end{tabular}

Gambar 1. Desain Penelitian

(Sugiyono, 2012)

Keterangan:

$\mathrm{O}_{1}=$ nilai pretest (sebelum diberi perlakuan)

$\mathrm{O}_{2}=$ nilai posttes (setelah diberi perlakuan)

Efektifitas modul pembelajaran terintegrasi STEM dianalisis secara kuantitatif berdasarkan data hasil pre-test dan post-test siswa. Dari kedua tes tersebut kemudian dianalisis menggunakan persamaan normalized Gain ( $N$-gain) untuk mengetahui efektifitas keterampilan berpikir siswa. Menurut Hake (dalam Suprianto et al., 2018) menyatakan bahwa persamaan normalized gain <n-gain> adalah hasil rata-rata nilai posttest dibagi dengan nilai pretest.

$$
\begin{array}{r}
<N-\text { gain }>=\frac{\left(s_{f}\right)-\left(s_{i}\right)}{100-\left(s_{i}\right)} \\
<N-\text { gain }>=\frac{\left(s_{f}\right)-\left(s_{i}\right)}{100-\left(s_{i}\right)}(3.2)
\end{array}
$$

Keterangan:

$$
\begin{array}{ll}
N-\text { gain } & =\text { gain ternormalisasi } \\
S_{f} & =\text { rata-rata nilai posttest } \\
S_{i} & =\text { rata-rata nilai pretest }
\end{array}
$$

\begin{tabular}{|c|c|}
\hline Nilai N-Gain & Kriteria \\
\hline$<N$-gain $>>0.70$ & Tinggi \\
\hline $\begin{array}{r}0.30 \leq<N-\text { gain }> \\
\leq 0.700\end{array}$ & Sedang \\
\hline$<N$-gain $><0.30$ & Rendah \\
\hline
\end{tabular}

Kriteria dari Normalized gain sebagaimana ditunjukan pada Tabel 1 berikut.

Tabel 1. Kriteria Normalized Gain

(Hake (dalam Suprianto et al., 2018))

\section{HASIL DAN PEMBAHASAN}

Pengujian modul untuk mengetahui efektif atau tidak dilakukan dengan 2 pengujian. Pengujian penggunaan modul pertama pada uji skala kecil atau uji skala terbatas. Uji skala terbatas dilakukan di MAN 1 Jember pada kelas X MIPA 2 sebanyak 10 siswa, sedangkan uji skala lapang atau uji skala besar dilakukan pada kelas X MIPA 3 sebanyak 20 siswa. Pelaksanaan kedua pengujian baik uji skala terbatas dilakukan secara daring melalui Google Meet.

Sebelum pembelajaran berlangsung, siswa diberikan pretest atau tes pendahuluan untuk mengetahui sejauh mana pengetahuan siswa tentang materi usaha dan energi. Pembelajaran yang dilakukan baik di skala terbatas maupun skala luas menggunakan 2 pertemuan dengan durasi masing-masing pertemuan 90 menit. Kegiatan yang dilakukan pada pertemuan pertama adalah mengerjakan pretest, pretest dikerjakan dalam waktu 30 menit sebelum pembelajaran dimulai, kemudian mempelajari modul fisika yang terintegrasi STEM pada kegiatan belajar 1.

Selanjutnya, pada pertemuan kedua dilanjutkan dengan kegiatan belajar 2 dan latihan soal, posttest, dan mengisi angket respon siswa setelah menggunakan modul fisika terintegrasi STEM pada pokok bahasan usaha dan energi. Pada uji coba skala luas rata-rata $N$-gain yang diperoleh 
lebih tinggi dari pada rata-rata $N$-gain pada uji coba skala terbatas. Pada Tabel 2 berikut merupakan rekapitulasi $N$-gain pada uji coba skala terbatas dan uji coba skala luas.

Tabel 2. Rekapitulasi Hasil Uji Coba Skala Terbatas dan Skala Luas

\begin{tabular}{l|r|r|r|r}
\hline \multicolumn{1}{c|}{ Uji Coba } & Pretest & 'osttest & V-gain & Kriteria \\
\hline Skala Terbatas & 66,1 & 85,6 & 0,55 & Sedang \\
Skala Luas & 56,35 & 87,95 & 0,71 & Tinggi \\
\hline
\end{tabular}

Berdasarkan Tabel 2 menunjukan bahwa nilai rata-rata pretest dan posttest pada uji skala terbatas sebesar 66.1 dan 85,6 sedangkan nilai rata-rata pada uji coba skala luas sebesar 56,35 dan 87,9. Nilai pretest dan posttest secara klasikal dianalisis untuk mengetahui peningkatan hasil belajar siswa ranah kognitif sebelum dan sesudah pembelajaran menggunakan uji $\mathrm{N}$-gain dan dikategorikan sesuai dengan kriteria berdasarkan Tabel 1. Berdasarkan hasil analisis data nilai rata-rata $N$-gain pada uji coba skala terbatas diperoleh nilai 0,55. Berdasarkan Tabel 1 nilai $N$-gain antara $0.30 \leq<N-$ gain $>\leq 0.70$ dengan kriteria sedang, sedangkan hasil analisis data nilai rata-rata $N$-gain pada uji coba skala besar diperoleh nilai 0,71 dengan kriteria tinggi. Sesuai dengan kriteria pada table 1 , rentan nilai $N$-gain $>0.70$ diinpretasikan dalam kriteria tinggi. Dengan demikian, pembelajaran dengan menggunakan modul fisika terintegrasi STEM efektif untuk digunakan dalam menunjang kegiatan belajar mengajar.

Efektivitas modul fisika terintegrasi STEM (Science, Technology, Engineering and Mathematics) pada materi usaha dan energi diketahui berdasarkan nilai pretest dan posttest siswa. Nilai pretest diambil pada skala terbatas sebanyak 10 siswa dan pada uji lapangan dengan jumlah sebanyak 20 siswa. Subyek penelitian berasal dari kelas X MIPA 2 dan X MIPA 3 di MAN 1 Jember. Soal pretest yang digunakan merupakan uraian berjumlah lima soal. Selanjutnya, siswa melakukan kegiatan pembelajaran menggunakan modul fisika terintegrasi STEM pada materi usaha dan energi.

Pembelajaran dilakukan selama dua kali pertemuan, karena dimusim pandemi covid-19 pertemuan setiap mata pelajaran dipangkas lebih sedikit dari biasanya. Pembelajaran dilakukan menggunakan Google Meet dalam setiap pertemuan. Setelah kegiatan pembelajaran selesai, siswa diberikan soal posttest yang dishare melalui Whattsap Group. Soal posttest yang diberikan merupakan soal yang mempunyai indikator yang sama dengan soal pretest. Soal posttest berjumlah lima soal uraian.

Hasil nilai pretest dan posttest dianalisis menggunakan uji efektifitas untuk mengetahui tingkat keefektifan modul. Nilai $N$-gain efektifitas yang diperoleh berdasarkan uji coba skala terbatas nilai $N$ gain sebesar 0,55 dengan kategori sedang. Hal tersebut dikarenakan pemilihan siswa pada uji skala terbatas dipilih secara acak. Berdasarkan hasil observasi peneliti, dari 10 siswa tersebut beberapa diantaranya termasuk dalam kategori hasil belajar rendah. Hal tersebut ditunjukkan oleh guru mapel fisika terkait hasil belajar masingmasing siswa pada materi sebelumnya kepada peneliti.

Sedangkan pada uji skala luas nilai $\mathrm{N}$ gain sebesar 0,71. Berdasarkan hasil observasi peneliti dan pemaparan guru mapel fisika terkait kelas yang digunakan sebagai uji skala luas, Beliau menuturkan bahwa hasil belajar siswa memang lebih tinggi jika dibandingkan dengan kelas pada uji skala terbatas, akan tetapi dalam hal respon, semangat dan keaktifan selama mengikuti proses pembelajaran, kelas pada uji skala terbatas 
lebih unggul dalam hal tersebut. Dikarenakan kelas pada uji skala terbatas sebagian besar merupakan anak ma'had yang dalam kesehariannya pemahaman yang didapat diluar jam sekolah menekankan pada pemahaman terhadap al-quran. Sehingga siswa merasa antusias selama mengikuti kegiatan belajar di sekolah dengan memperoleh penambahan ilmu selain pembelajaran agama.

Berdasarkan analisis keefektifan bahwa modul fisika terintegrasi STEM (Science, Technology, Engineering and Mathematics) dalam kategori efektif. Hal ini sesuai dengan penelitian (Almuharomah et al.,2019) tentang modul STEM terintegrasi kearifan lokal, dalam penelitiannya memperoleh nilai $\mathrm{N}$-gain pada kelompok kecil sebesar 0,39 dengan kategori sedang. Sedangkan pada kelompok besar mendapat nilai $N$-gain sebesar 0,92 dengan kategori tinggi. Modul dinyatakan efektif apabila hasil uji coba yang dilakukan menunjukkan kategori baik (Retnowati et al., 2020). Modul cetak efektif untuk meningkatkan hasil belajar siswa (Puspitasari, 2019). Adanya peningkatan nilai $N$-gain menunjukkah bahwa modul efektif digunakan dalam pembelajaran dan dapat menjadi pendamping buku paket di sekolah (Listiana et al, 2019).

\section{SIMPULAN DAN SARAN}

Berdasarkan data yang diperoleh pada hasil dan pembahasan pengembangan modul fisika terintegrasi STEM (Science, Technology, Engineering and Mathematics) pada pokok bahasan usaha dan energi, maka dapat disimpulkan bahwa efektifitas modul fisika terintegrasi STEM pada pokok bahasan usaha dan energi dapat meningkatkan hasil belajar siswa pada aspek kognitif dan memperoleh nilai $\mathrm{N}$-gain sebesar 0,71. Analisis data menunjukkan terdapat perbedaan sebelum dan sesudah menggunakan modul fisika terintegrasi STEM. Oleh karena itu, modul fisika terintegrasi STEM pada pokok bahasan usaha dan energi dapat dikatakan efektif dan dapat digunakan dalam pembelajaran. Saran penelitian ini yaitu penelitian ini dapat dikembangkan dengan mengintegrasikan STEM dalam pembelajaran maupun materi lainnya. Selain itu, penelitian ini juga dapat dijadikan rujukan untuk penelitian selanjutnya.

\section{DAFTAR PUSTAKA}

Akaygun, S., \& Aslan-Tutak, F. (2016). STEM Images Revealing STEM Conceptions of Pre-Service Chemistry and Mathematics Teachers. International Journal of Education in Mathematics, Science and Technology. 4(1): 56.

Almuharomah, F. A., Mayasari, T., \& Kurniadi, E. (2019). Pengembangan Modul Fisika STEM Terintegrasi Kearifan Lokal "Beduk" untuk Meningkatkan Kemampuan Berpikir Kreatif Siswa SMP. Berkala Ilmiah Pendidikan Fisika. 7(1): 1.

Bekti, N., Dwi, W., Gola, N., Raudhotus, R., Nuraini, L., Kusuma, F., \& Anggraeni, A. (2021). Pengembangan Modul Interaktif Berbasis Macromedia Flash 8 Pada Materi Optik Geometri. Jurnal Hasil Kajian, Inovasi, dan Aplikasi Pendidikan Fisika. 7(1): 123-135.

Darmawan, A., Ramadhana, Z., Hadi, P., \& Suyudi, A. (2019). Pemahaman Konsep Mahasiswa Calon Guru pada Topik Usaha dan Energi melalui Representasi Grafik. Jurnal Inovasi Pendidikan Fisika dan Integrasinya. 02(02): 41-54.

Dewi, W. A. F. (2020). Dampak COVID-19 terhadap Implementasi Pembelajaran 
Daring di Sekolah Dasar. Edukatif: Jurnal Ilmu Pendidikan. 2(1): 55-61.

Efendi, D. N., Supriadi, B., \& Nuraini, L. (2021). Analisis Respon Siswa Terhadap Media Animasi Powerpoint Pokok Bahasan Kalor. Jurnal Pembelajaran Fisika. 10(2): 49-53.

Fatikhah, I., \& Izzati, N. (2015). Pengembangan Modul Pembelajaran Matematika Bermuatan Emotion Quotient Pada Pokok Bahasan Himpunan. Eduma: Mathematics Education Learning and Teaching. 4(2): 46-61.

Fikri, M. R., Muslim, M., Purwana, U., \& Karyawan, K. (2019). Upaya Meningkatkan Kreativitas Siswa Dalam Membuat Karya Fisika Melalui Model Pembelajaran Berbasis STEM (Science, Technology, Engineering and Mathematics) Pada Materi Fluida Statis. WaPFi (Wahana Pendidikan Fisika). 4(1):73.

Istiadah, F. N. (2020). Teori Belajar dalam Pendidikan. Tasikmalaya: Edu Publisher.

Krajcik, J., \& Delen, İ. (2017). Engaging learners in STEM education. Eesti Haridusteaduste Ajakiri. Estonian Journal of Education, 5(1): 35-58.

Listiana, L., Abdurrahman, A., Suyatna, A., \& Nuangchalerm, P. (2019). The Effect of Newtonian Dynamics STEM-Integrated Learning Strategy to Increase Scientific Literacy of Senior High School Students. Jurnal Ilmiah Pendidikan Fisika Al-Biruni. 8(1), 43-52.

Maison, M., Lestari, N., \& Widaningtyas, A. (2020). Identifikasi Miskonsepsi Siswa Pada Materi Usaha Dan Energi. Jurnal Penelitian Pendidikan IPA. 6(1): 32-39. Universitas Mataram.

Nofrion. (2016). Komunikasi Pendidikan. Jakarta: Kencana.
Pawilen, G. T., \& Yuzon, M. R. A. (2019). Planning a Science, Technology, Engineering, and Mathematics (STEM) Curriculum for Young Children: A Collaborative Project for Pre-service Teacher Education Students conditions of the Creative Commons Attribution license (CC BY-NC-ND). International Journal of Curriculum and Instruction. 11(2):130-146.

Permanasari, A. (2016). STEM Education: Inovasi dalam Pembelajaran Sains. Prosiding Seminar Nasional Pendidikan Sains (SNPS) (pp. 23-24).

Puspitasari, A. D. (2019). Penerapan Media Pembelajaran Fisika Menggunakan Modul Cetak dan Modul Elektronik pada Siswa SMA. Jurnal Pendidikan Fisika. 7(1):17-25.

Rahmadi, A. (2021). Analisis Model Pembelajaran Daring Konsep Getaran dan Gelombang Pada Siswa Smk di Masa Pandemi Covid-19. Jurnal Pembelajaran Fisika. 10(3): 98-105.

Retnowati, S., Riyadi \& Subanti, S. (2020). the Stem Approach : the Development of Rectangular. International Online Journal of Education and Teaching (IOJET), 7(1)., 7(The development of rectangular module to improve critical thinking skill. International). 2-15.

Rigianti, H. A. (2020). Kendala Pembelajaran Daring Guru Sekolah Dasar di Kabupaten Banjarnegara. 7(2):297-302.

Simarmata, J., L. Simanihuruk, R. Ramadhani, M. Safitri, D. Wahuni, \& A. Iskandar. (2019). Pembelajaran STEM Berbasis HOTS dan Penerapannya. Medan: Yayasan Kita Menulis.

Sukiminiandari, Y. P., Budi, A. S., \& Supriyati, Y. (2015). Pengembangan Modul Fisika dengan Pendekatan 
Saintifik. Prosiding Seminar Nasional Fisika (E-Journal) SNF2015, IV, 161164.

Suprianto, S., Kholida, S. I., Andi, H. J., \& Mahardika, I. K. (2018). The Effectiveness of Basic Physics Experiment Module Based on Guided Inquiry Model in Improving Hard Skills and Soft Skills of Prospective Physics Teachers. Jurnal Pendidikan Fisika Indonesia, 14(2):52-59.

Utami, I. S., Septiyanto, R. F., Wibowo, F. C., \& Suryana, A. (2017). Pengembangan STEM-A (Science, Technology, Engineering, Mathematic and Animation) Berbasis Kearifan Lokal dalam Pembelajaran Fisika. Jurnal Ilmiah Pendidikan Fisika AlBiruni. 6(1):67-73. 